\title{
Construindo saberes e compartilhando experiências em Português Brasileiro como Língua Estrangeira1
}

\author{
Building knowledge and sharing experiences in Brazilian \\ Portuguese as a Foreign Language
}

\section{Construyendo conocimiento y compartiendo experiencias en Portugués Brasileño como Lengua Extranjera}

\author{
Anderson Lins Rodrigues ${ }^{2}$ (iD https://orcid.org/\%200000-0001-6619-9321 \\ José Lucas Campos Antunes dos Santos ${ }^{3}$ (iD https://orcid.org/0000-0001-7821-148X
}

\begin{abstract}
RESUMO: Neste trabalho, compartilhamos o percurso de sistematização e execução de um curso remoto de Português Brasileiro como Língua Estrangeira (PBLE), por nós ministrado, no segundo semestre de 2020. A oferta desse curso está circunscrita a um conjunto de ações do processo de internacionalização da Universidade Estadual de Santa Cruz. O curso de PBLE, portanto, emerge como uma ação viabilizadora do desenvolvimento de estratégias de ensino, aprendizagem e fortalecimento da língua brasileira no cenário linguístico internacional (MOITA LOPES, 2016). Nesse contexto de internacionalização e, também, como desdobramento de algumas inquietações surgidas ao longo do referido curso, sobretudo no que se refere à necessidade de revisão do ideal homogêneo de língua nacional, numa perspectiva decolonial sobre a constituição políticolinguística de amefricanidade e "Pretuguês" (GONZALEZ, 2020), objetivamos discutir abordagens e metodologias do ensino de PBLE, bem como refletir sobre o processo de formação de professores e de pesquisas nessa área. Com essa experiência, constatamos que a formação docente e o ensino de PBLE devem considerar as especificidades corriqueiras e cotidianas da vida linguística no Brasil, levando em conta as contribuições negra e indígena na formação do vernáculo brasileiro.
\end{abstract}

PALAVRAS-CHAVE: Português Brasileiro como Língua Estrangeira. Ensino e Pesquisa.

\footnotetext{
${ }^{1} \mathrm{O}$ título deste artigo orienta-se a partir do profícuo espaço de discussões e reflexões sobre os sentidos que contornam o ensino-aprendizagem de Português Brasileiro como língua estrangeira em nosso grupo de trabalhos, fazendo menção às considerações deste texto apresentadas no evento online Language Week / Idea Factory / Jornada de Ensino de Português Língua Estrangeira da Universidade Estadual de Santa Cruz no segundo semestre de 2021.

2Doutor em Letras pela Universidade Federal de Pernambuco. Professor do Departamento de Letras e Artes da Universidade Estadual de Santa Cruz. E-mail: alrodrigues@uesc.br

${ }^{3}$ Licenciado em Letras - Português/Inglês pela Universidade Estadual de Santa Cruz. E-mail: cans.luc@gmail.com
} 
Formação Docente.

ABSTRACT: In this paper, we intend to share the path of systematization and execution of a remote course in Brazilian Portuguese as a Foreign Language (PBLE), which we taught in the second half of 2020. The offer of this course is limited to a set of actions in the internationalization process of the State University of Santa Cruz. The PBLE course, therefore, emerges as an action that enables the development of teaching, learning, and strategies for the Brazilian language in the international linguistic scenario (MOITA LOPES, 2016). In this context of internationalization and also as a result of some concerns that emerged throughout the course, especially about the necessity to revise the homogeneous ideal of the national language in a decolonial perspective, taking into account the political-linguistic constitution of Amefricanity and "Pretuguês" (GONZALEZ, 2020), we aim to discuss approaches and methodologies for teaching PBLE, as well as reflect on the process of teacher education and research in this area. With this experience, we found that teacher education and teaching of PBLE must consider the commonplace and everyday specificities of linguistic life in Brazil, taking into account the black and indigenous contributions in the formation of the Brazilian vernacular.

KEYWORDS: Brazilian Portuguese as Foreign Language. Teaching and Research. Teachers Education.

RESUMEN: En este trabajo, pretendemos compartir el camino de la sistematización y ejecución de un curso remoto de Portugués Brasileño como Lengua Extranjera (PBLE), que impartimos en el segundo semestre de 2020. La oferta de este curso se limita a un conjunto de acciones en el proceso de internacionalización de la Universidad Estadual de Santa Cruz. El curso PBLE, por tanto, surge como una acción que posibilita el desarrollo de estrategias de enseñanza, aprendizaje y fortalecimiento de la lengua brasileña en el escenario lingüístico internacional (MOITA LOPES, 2016). En este contexto de internacionalización y también como resultado de algunas preocupaciones que surgieron a lo largo del curso, especialmente en lo que se refiere a la necesidad de revisar el ideal homogéneo de la lengua nacional, en una perspectiva descolonial sobre la constitución político-lingüística de la Amefricanidad y el "Pretuguês" (GONZALEZ, 2020), buscamos discutir enfoques y metodologías para la enseñanza de PBLE, así como reflexionar sobre el proceso de formación e investigación docente en esta área. Con esta experiencia, encontramos que la formación docente y la enseñanza de PBLE deben considerar las especificidades comunes y cotidianas de la vida lingüística en Brasil, tomando en cuenta las contribuciones negras e indígenas en la formación de la lengua vernácula brasileña.

PALABRAS CLAVE: Portugués Brasileño como Lengua Extranjera. Docencia e Investigación. Formación de Profesores.

\section{Palavras iniciais - um gesto de aceno}

$\mathrm{O}$ ano de 2020 foi um ano rico em aprendizados. Fomos chamados à mudança num contexto em que a impermanência das coisas do mundo apresentou-se de forma trágica e dramática às mais diversas sociedades humanas do planeta, exigindo profundas mudanças de paradigma. Estamos vivendo essa atmosfera, somos nós os agentes responsáveis por essa mudança. Nesse sentido, o ensino de língua portuguesa para estrangeiros configura-se num cenário marcado por uma crise sanitária decorrente das crises humanitárias atravessadas por golpes de estado, migrações em massa - 
consequência das crises políticas e econômicas instauradas em países subdesenvolvidos - e a pandemia de um vírus altamente contagioso e letal.

Não concebemos outra forma de iniciar esse trabalho senão contextualizando e situando o momento histórico e de crise global que estamos atravessando. Assim procedemos porque, além da necessidade de articular essas reflexões em um tempoespaço específico, também entendemos que elas emergem como resultado do que estamos vivenciando. Isto é, os flagelos sociais, que têm impactado a vida de muitas pessoas, tendo como desdobramento os grandes fluxos migratórios, refletem na própria demanda de muitos estrangeiros que, chegando ao Brasil, recorrem ao conhecimento da língua que aqui praticamos com vistas à inserção em nossa sociedade.

Por essa razão, nos preocupamos em tratar das condições de emergência de oferta de um curso de língua para estrangeiros num cenário de pandemia da covid-19 e de isolamento social, em que processos históricos de fluxo migratório acentuam-se e mostram-se, cada vez mais, desafiadores a nós, professores e pesquisadores comprometidos com a transformação dessas realidades.

Dito isso, no que toca à elaboração do presente trabalho, temos por objetivo: i. discutir abordagens e metodologias do ensino de Português Brasileiro como Língua Estrangeira (PBLE) ${ }^{4}$, bem como ii. refletir sobre o processo de formação de professores e de pesquisas nessa área de PBLE, considerando a necessidade de revisão do ideal homogêneo de língua nacional numa perspectiva decolonial sobre a constituição políticolinguística de amefricanidade e "pretuguês" (ALMEIDA, 2020; GONZALEZ, 2020). Nosso percurso argumentativo acontecerá pari passu com a apresentação dos caminhos teóricometodológicos desse curso de português brasileiro, que aconteceu no âmbito do Centro de Línguas e Internacionalização da Universidade Estadual de Santa Cruz (UESC), e foi ofertado para cidadãos estrangeiros durante o segundo semestre de 2020.

É preciso dizer que a oferta do curso Língua Portuguesa Nas Relações De Trabalho: Curso Introdutório para Estrangeiros faz parte do processo de internacionalização da UESC que requer, dentre outras ações, o fomento a uma política de fortalecimento a

\footnotetext{
4 Utilizamos aqui a nomenclatura PBLE por entender a necessidade e importância de demarcar um território de identidade linguística que (re)inscreva os sentidos identitário-linguísticos de um Português do Brasil, e não no Brasil. A escolha é consciente de outras nomenclaturas e campos de pesquisa em Português como Língua Adicional (PLA), Português Língua de Acolhimento (PLAC) e Português em contextos de migração e refúgio, no entanto, optamos por atualizar a nomenclatura do campo de estudos do qual parte nossas reflexões e prática docente, o Português como Língua Estrangeira (PLE).
} 
iniciativas que contemplem a proficiência de estudantes estrangeiros (intercambistas) nos mais diversos Programas de Graduação e Pós-Graduação. A Resolução CONSU 07/2018 é o documento que chancela as ações em pesquisa e extensão - direcionadas a professores, discentes, funcionários e comunidade - circunscritas ao campo de atuação com fulcro na oferta de línguas estrangeiras enquanto componente integrante da mencionada política de internacionalização.

Nesse cenário político-linguístico, o ensino de Português como língua estrangeira figura como uma das possibilidades preconizadas pelos Princípios e pelas Diretrizes dessa Política Linguística de Internacionalização da nossa universidade. A nossa proposta de ensino, então, emerge como uma ação viabilizadora do desenvolvimento de estratégias de ensino, aprendizagem e fortalecimento da língua brasileira nesse cenário linguístico internacional (MOITA LOPES, 2016).

A oferta desse curso, inicialmente, voltava-se para um público de estudantes intercambistas de graduação e pós-graduação, mas, sabedores da demanda de cidadãos que estavam na condição de refugiados, com o agravamento de crises humanitárias em razão de questões políticas, econômicas e sanitárias, sobretudo, nos países da América Latina, resolvemos ampliar o público-alvo. Com isso, recebemos inscrições de haitianos, venezuelanos, chilenos, franceses, búlgaros, dentre outros. Em sua grande maioria, pessoas que se encontravam em situação de vulnerabilidade social, refugiados em busca de conhecer o português brasileiros para ter melhores condições de ingresso no mercado de trabalho do Brasil.

Com base nessa breve exposição, a proposta teórica que alicerça esse curso tangencia a ideia de que a finalidade primeira do ensino e da aprendizagem de uma língua estrangeira está diretamente articulada à necessidade de que as/os estudantes se tornem aptos a se comunicar nessa língua, com vistas a atender às suas necessidades. Por essa razão, a concepção que adotamos considerou que os objetivos de aprendizagem fossem delineados em termos comunicativos, o que só poderia ser alcançado mediante as reais necessidades de comunicação dos aprendentes.

Tivemos, então, como principal respaldo teórico e metodológico os estudos relacionados à abordagem comunicativa, que nos propõe pensar a aprendizagem como resultado advindo da interação social (BORGES, 2012). Com base nessa perspectiva, levamos em conta que cada ação de ensino e aprendizagem precisa ser viabilizada por um projeto de comunicação. Ao nos reportamos à metodologia de comunicação, estamos 
certos de que essa abordagem exige uma ação que será efetuada via língua(gem) por meio de um determinado campo da atividade humana (BAKHTIN, 1997) que, por sua vez, inscreve os participantes da interlocução em uma interação social concreta, ou seja, organizada/sistematizada pelos gêneros e compartilhada por um grupo social específico, que demanda certos objetivos.

\section{Por dentro do curso de PBLE da UESC}

Começamos a sessão chamando a atenção para o Brasil e seu lugar na Améfrica do Sul (GONZALEZ, 2020), por termos em nossas turmas uma maioria sul-americana, composta, em grande parte, por venezuelanos, colombianos, chilenos, hondurenhos e mexicanos, mas não só, houve imigrantes da Europa também. Em termos da relação entre o Brasil e os demais países da América do Sul, é latente as fraturas decorrentes do colonialismo, estreia de toda a barbárie que experienciamos, hoje, em se tratando da $6^{a}$ Zona de África, a diáspora africana do Brasil em território historicamente e originariamente indígena. Segundo o Relatório Anual do Observatório das Migrações Internacionais, haitianos, venezuelanos e colombianos são as três principais nacionalidades que formam o grupo de imigrantes no Brasil de 2018.

Apesar de formarem uma turma majoritariamente do Sul, configurava-se bastante heterogênea no que tangia às suas motivações de deslocamento; havia estudantes em situação de deslocamento forçado e imigrantes com histórias e experiências diversas que objetivavam, no Brasil, um lugar possível de melhorar sua qualidade de vida no caminho do desenvolvimento intelectual e profissional. Havia, por exemplo, sul-americanos tanto na condição de estudantes de pós-graduação, quanto de imigrantes e refugiados à procura de emprego.

Seja por questões fronteiriças ou de ordem política, econômica e cultural, o Brasil tem se tornado, cada vez mais, o destino de imigrantes e refugiados em busca de aprimoramento intelectual, profissional e de refúgio. No âmbito das políticas linguísticas, a área de Português como Língua Estrangeira emerge como uma das formas de inserção do Brasil nas injunções do mercado internacional e de seu lugar de autoria no processo de instrumentalização e institucionalização da língua nacional, o [...] "que consistiria em configurar um lugar de enunciação institucional e internacionalmente legitimado que autoriza um saber sobre a língua nacional passível de ser exportado" (ZOPPI-FONTANA; DINIZ, 2008, p. 90). 
A iniciativa de oferta desse curso caminha, portanto, no fluxo dos processos de gramatização brasileira, os quais não estão dissociados dos impactos da rigidez hierárquica e homogeneizante das práticas colonizadoras que buscam uniformizar e escamotear o racismo que funda as relações linguísticas e culturais neste lado das américas. A língua, não obstante, ocupa esse lugar no imaginário compartilhado sobre a ideia de um Brasil monolíngue e, com isso, escamoteia-se a sua diversidade multilíngue e multicultural. Nesta trilha de invisibilidades e apagamentos, o Brasil figura uma contradição diante suas proposições humanitárias de acolhimento e as barreiras linguísticas na integração das populações em deslocamentos forçados.

Sobre as estratégias para a viabilização do curso e sondagem acerca dos interesses do nosso público-alvo, elaboramos, em um primeiro momento, um formulário com a intenção de conhecer os interesses de aprendizagem dos cursistas, partindo do seguinte questionamento: O que você busca em um curso de Português Brasileiro como Língua Estrangeira? na plataforma google forms. Através deste formulário, traçamos o perfil de nossas/os estudantes, considerando suas motivações para fazer o curso, as experiências com o português brasileiro, bem como as dificuldades com as modalidades oral e escrita. Por este viés, o formulário funciona num propósito dialógico, em que as pessoas são o centro das atividades que irão atingi-las de alguma forma no desenho do curso. Abaixo, trouxemos uma das questões do supracitado formulário e a resposta de uma aluna venezuelana.

Tabela 1 - O Português Brasileiro e as pretensões das/os estudantes

\begin{tabular}{c|l|}
\hline Pergunta & $\begin{array}{l}\text { De que forma o conhecimento do português brasileiro pode lhe ajudar a viver } \\
\text { melhor neste país, seja nas relações de trabalho, na universidade ou em } \\
\text { qualquer atividade social realizada por um cidadão estrangeiro? }\end{array}$ \\
\hline Nacionalidade $^{5}$ & \multicolumn{1}{|c}{ Venezuelana } \\
\hline Resposta & $\begin{array}{l}\text { Posso ter mais oportunidade de optar a um emprego e realizar cursos } \\
\text { profesionalizantes. }\end{array}$ \\
\hline
\end{tabular}

Fonte: Os autores, 2021.

Com base nessa e em outras respostas, nos responsabilizamos pela elaboração de

\footnotetext{
${ }^{5}$ As nacionalidades estão retratadas de acordo com as respostas das/os estudantes no quesito "nacionalidade" do formulário de reconhecimento.
} 
um curso que pudesse ser ferramenta de respeito aos direitos garantidos a essas populações. Trabalhamos, então, com a Lei no 13.445 de 2017, hoje chamada de Lei da Migração, tratando dos documentos necessários ao estrangeiro no Brasil (Cédula de Identidade para Estrangeiros (RNE) e o Cartão do Cadastro de Pessoas Físicas (CPF/MF)) e situando nossos/as estudantes para seus usos e funcionalidades na vida cotidiana.

Em razão dessa exposição, justificamos a nossa preocupação em ofertar um curso com essa envergadura, ou seja, do português brasileiro nas relações de trabalho. 0 trato com gêneros discursivos afins a essa cena enunciativa, tais como a elaboração de currículo e a entrevista de emprego, objetivaram a utilização da língua em uma situação formal e como agir dentro desse contexto. Se as proposições do curso tinham no título o mundo do trabalho, o público que o compunha, no entanto, era bastante heterogêneo e multifacetado, tornando mais desafiador o tear de aulas que atingissem um objetivo comum entre todas/os.

Ainda fazendo referência ao questionário aplicado previamente com a turma, vejamos as expectativas deste estudante de pós-graduação:

Tabela 2 - O Português Brasileiro e as pretensões das/os estudantes

\begin{tabular}{c|l|}
\hline Pergunta & $\begin{array}{l}\text { De que forma o conhecimento do português brasileiro pode lhe ajudar } \\
\text { a viver melhor neste país, seja nas relações de trabalho, na } \\
\text { universidade ou em qualquer atividade social realizada por um cidadão } \\
\text { estrangeiro? }\end{array}$ \\
\hline Nacionalidade & \multicolumn{1}{|c|}{ Colombiano } \\
\hline Resposta & $\begin{array}{l}\text { Fazer um mestrado em literatura em português representa muitos } \\
\text { desafios: compreender, interpretar e escrever textos } \\
\text { acadêmicos. Aprender mais sobre esse idioma não apenas me } \\
\text { ajudará nesse aspecto, mas também melhorará minha comunicaçao } \\
\text { com meus amigos. A propósito, preciso aprender mais sobre as gírias } \\
\text { baianas - ou como prefiro chamá-las - o portugues do futuro. (Grifos } \\
\text { nossos) }\end{array}$ \\
\hline
\end{tabular}

Fonte: Os autores, 2021

Nesta resposta, o estudante é explícito em tratar seus objetivos de aprendizagem (grifos), o que, de certo modo, é tangente à proposição institucional, mas não deixa de existir enquanto demanda da comunidade acadêmica da UESC. No seio desses contrastes, buscamos aproximações que convergem nos propósitos comuns de aprendizagem da língua para todas/os discentes. 
Compreendendo os objetivos de aprendizagem divergentes, dividimos as/os estudantes em dois grupos (estudantes de pós-graduação e estudantes em busca de trabalho). Essa divisão ocorreu na metade do curso, momento em que direcionamos os conteúdos linguísticos a partir das demandas referentes a esses dois grupos. Dessa maneira, pudemos corresponder às intenções das/os estudantes em aprender conteúdos gramaticais (mesmo que ainda apoiados numa percepção colonizada de língua, fundamentada no paradigma gramatical greco-romano) e a estrutura textual relacionadas à elaboração de gêneros textuais acadêmicos, bem como as variedades linguísticas para comunicação e relações interpessoais em contextos formais e informais. Sobre o aspecto comunicacional, foram recorrentes a convergência entre as respostas:

Tabela 3 - O Português Brasileiro e as pretensões das/os estudantes

\begin{tabular}{|c|c|}
\hline Nacionalidade & Mexicana \\
\hline Resposta & $\begin{array}{l}\text { O conhecimento do portugues brasileiro me ajudaria a tenher posibilidade de } \\
\text { postular a um trabalho de mi licenciatura e conocer a más personas en el país. }\end{array}$ \\
\hline Nacionalidade & Colombiana \\
\hline Resposta & $\begin{array}{l}\text { isso me ajuda a me comunicar melhor com as pessoas. além de poder } \\
\text { participar de conversas mais profundas com meus professores e colegas }\end{array}$ \\
\hline Nacionalidade & Venezuelano \\
\hline Resposta & $\begin{array}{l}\text { Ampliar os contatos e a comunicação, conhecer melhor o povo brasileiro e } \\
\text { defender nossos dereitos }\end{array}$ \\
\hline Nacionalidade & Venezuelano \\
\hline Resposta & $\begin{array}{l}\text { Ser capaz de me comunicar de forma clara; entender o que as pessoas falam } \\
\text { comigo e poder desenvolver minhas atividades de estudo }\end{array}$ \\
\hline Nacionalidade & Cidadão do Mundo \\
\hline Resposta & Obviamente, facilitando a comunicação \\
\hline
\end{tabular}

Fonte: Os autores, 2021.

Ante o exposto, observamos o alinhamento entre o aprendizado da língua para desenvolvimento intelectual e profissional, em que a comunicação é o ponto de partida para a efetivação desses conhecimentos linguísticos na vida social de imigrantes e refugiados. O desenvolvimento das competências comunicativas se deu explorando aspectos fonético-fonológicos da língua, marcadores conversacionais e expressões idiomáticas, bem como as situações comunicativas de entrevista de emprego. Para tanto, 
foi imprescindível o trato da língua(gem) intimamente ligado à cultura, pois, quando se diz, fala-se de um lugar social atravessado por experiências que delimitam as fronteiras de suas subjetividades. Sob essa ótica, a aprendizagem de PBLE passa a ser espaço de aceitação da configuração múltipla do sujeito e sua interação verbal na sociedade.

Com essa reflexão, é imprescindível que façamos referência a Lélia Gonzalez (2020) para pensarmos as cartografias impostas pelo ocidente na materialização do imaginário homogêneo e cristalizado do que seria a língua portuguesa: tal materialização foi latente em algumas/uns das/os estudantes de nossa turma, que reivindicavam um ensino prescritivo, pautado na tradição gramatical greco-romana. Nesse contexto, pensamos o quanto somos atravessados por um continuum colonial que orienta nossas práticas e valores enquanto sociedade forjada pelo sistema capitalista racializante nas américas.

Acreditamos ser esse o maior desafio a ser enfrentado para o caminho de uma real liberdade e independência do jugo ocidental-cristão, que produziu e mantém desigualdades linguísticas, sociais, raciais e de gênero nas sociedades pós-coloniais. Estamos nos referindo ao drama epistemológico que é fruto da imposição hierarquizante da língua e da cultura greco-romana sobre as subjetividades colonizadas (africanos e indígenas). Trata-se de refletir, portanto, sobre o impacto de tais imposições sobre uma maioria minorizada; em linhas gerais, a América é muito mais Ameríndia e Amefricana que latina (GONZALEZ, 2020). A propósito, vejamos, nas páginas seguintes, como essas proposições colidem sobre a ideia de língua e sua práxis no ensino de Português como Língua Estrangeira.

Em se tratando da imagem internacional do Brasil, é possível detectarmos como a colonialidade encarrega-se de projetar uma imagem paradoxal em relação à sua língua e cultura, a exemplo do aclamado mito da democracia racial e seu impacto na elaboração do imaginário sobre língua, cultura e nação brasileira. Nesse espectro, são operacionalizadas categorias que limitam e circunscrevem a ideia de língua, raça, gênero e nação, bem como seu impacto na elaboração de imagens cristalizadas e homogêneas sobre a língua e a cultura brasileira.

É importante, por isso, refletirmos sobre o ensino de línguas, uma vez que o professor que se forma nos atuais cursos de Letras vê-se o tempo todo confrontado pelas velhas concepções de língua(gem), seja por seu alunado ou pelas instituições de ensino em que trabalha. $\mathrm{O}$ que não foi diferente em nossa experiência no referido curso. Um de 
nossos professores foi, inclusive, alvo de críticas por parte de estudantes de nacionalidades europeias depois de uma discordância em relação aos efeitos do colonialismo nas relações de trabalho no Brasil. Fomos acusados de ofertar um curso sobre cultura do Brasil, sobre relações étnico-raciais, e não um curso sobre Língua Portuguesa, apesar de estarmos mediando as reflexões a partir de gêneros discursivos, como músicas, matérias de jornal, obras de arte etc.

Essas críticas aconteceram em uma das aulas sobre as condições e relações de trabalho no Brasil. Trouxemos a música Trabalhador, do ator, cantor e compositor Seu Jorge. Com esse texto, discutimos as desigualdades nas relações de trabalho no país como reflexo de seu sistema econômico. Durante toda a exposição dos aspectos linguísticos, políticos e culturais da música, as/os estudantes brancos e europeus insistiam no seu esvaziamento, tratando-o como uma música "triste e sem soluções para a questão do trabalho no Brasil", ou mesmo que "não é culpa dos portugueses e espanhóis [a condição da população negra]". Vale ressaltar que a canção é denúncia da colonialidade em sua vertente de exploração econômica do grupo dominante sobre o grupo dominado, o que explica as desigualdades raciais no mundo do trabalho.

É nesse sentido que o racismo - enquanto articulação ideológica e conjunto de práticas - denota sua eficácia estrutural na medida em que esta estabelece uma divisão racial do trabalho e é compartilhado por todas as formações socioeconômicas capitalistas e multirraciais contemporâneas. Em termos de manutenção do equilíbrio do sistema como um todo, ele é um dos critérios de maior importância na articulação dos mecanismos de recrutamento para as posições na estrutura de classes e no sistema da estratificação social (GONZÁLEZ, 2020, p. 35).

No escopo desse projeto, raça e classe articulam-se para elaboração e naturalização de lugares sociais num contexto capitalista e multirracial como o nosso. Talvez essa relação explique as diferenças entre os dois grandes fluxos migratórios para o Brasil, um primeiro promovido pelo governo, absorvendo imigrantes europeus num projeto de embranquecimento e europeização do país, bem como a ocupação de determinados postos de trabalho; e um outro, marcado por crises humanitárias de ordem sócio-político-econômica perpetradas pelos imperialismos do norte sobre o sul.

Em termos de como essa realidade se impõe na divisão racial do trabalho, não é preciso esforço para perceber que os principais alvos da xenofobia que marca a ascensão de uma extrema direita no governo do Brasil são imigrantes haitianos e venezuelanos, os 
quais estariam "tirando trabalho dos brasileiros". Com base nessas projeções enunciativas, o mestre Dr. Kabengele Munanga exprime os efeitos do racismo na formação das relações sociais, baseadas fundamentalmente na raça, como é o caso das sociedades pós-coloniais:

[...] Em nome das chamadas raças, inúmeras atrocidades foram cometidas nesta humanidade: genocídio de milhões de índios nas américas, eliminação sistemática de milhões de judeus e ciganos durante a Segunda Guerra Mundial. Como se não bastasse o antissemitismo, a persistência dos mecanismos de discriminação racial na África do Sul durante a Apartheid, nos Estados Unidos, na Europa e em todos os países da América do Sul encabeçados pelo Brasil e em outros cantos do mundo demonstra claramente que o racismo é um fato que confere à "raça" sua realidade política e social (MUNANGA, 2020, p. 15).

Ora, quando refletimos sobre o impacto do colonialismo nas relações sociais, é imprescindível que não falemos em culpa, mas em responsabilidade, uma vez que [...] "ideologicamente o neocolonialismo assentou-se no discurso da inferioridade racial dos povos colonizados que, segundo seus formuladores, estariam fadados à desorganização política e ao subdesenvolvimento" (ALMEIDA, 2020, p. 30). Assim, criam-se as justificativas para continuidade da barbárie sob os moldes neocoloniais, afinal os "portugueses e espanhóis não têm culpa".

É importante compreender, a esse respeito, como as questões de raça são centrais para a análise das experiências de professores e estudantes em sala de aula. Neste fluxo, o Letramento Racial Crítico (FERREIRA, 2014) é o caminho pelo qual nos conscientizamos da centralidade que raça e racismo se ocupam na organização e estruturação da sociedade, consequentemente em nossas práticas sociais. Para tanto, Ferreira (2014, p. 245) discute as atribuições de sentidos sobre as identidades raciais branca e negra a partir de narrativas autobiográficas acerca da construção destas identidades na língua(gem) na medida em que propõe

[...] uma reflexão com uma discussão articulada sobre a função das histórias e da cultura e da maneira como as histórias são historicamente e socialmente posicionadas à medida que contamos. [...] Nas histórias contadas por brancos é possível perceber o discurso ideológico de "não ver cor" $^{\prime \prime}$ (FERREIRA, 2014, p. 245)

Nesse sentido, o letramento racial crítico mobiliza identidades de raça branca e negra para refletir sobre como raça e racismo estão estruturados na sociedade. A situação descrita nas linhas a seguir tem, na Teoria Racial Crítica, o ponto nodal em que o conhecimento experiencial ocupa no trabalho de análise e reflexão das práticas sociais 
que organizam as relações de poder na sociedade através da linguagem. Nos moldes de um ensino prescritivo de formas e fórmulas linguísticas, a linguagem estaria

aqui como ligada às injustiças sociais ( $\mathrm{e}$, no nosso caso, mais especificamente à racial), porque elas parecem ser frequentemente materializadas na linguagem, com o uso de ideologias sobre língua/linguagem, com a construção de mitos e um repertório linguístico usado para dominação (NASCIMENTO, 2019, p. 213).

A discordância esteia-se, então, numa postura ideológica fundamentada no vitimismo das populações amefricanas (GONZALEZ, 2020) frente à barbárie colonial. Tal postura recorre a um discurso de negação e dúvida sobre o impacto das relações étnicoraciais para compreensão da língua, da cultura e da economia brasileira, e de como esses sentidos são constituintes do tecido social brasileiro.

Enquanto professores-pesquisadores, precisamos, portanto, desvelar a emergência de novos paradigmas conceituais sobre a língua(gem) e dar consequência a seu impacto na educação linguística em um quadro de internacionalização do Português Brasileiro. Esta emergência volta-se, então, para os percursos críticos traçados nos campos da Literatura, Antropologia e Filosofia que, agora, encontram-se confrontados no campo da Linguística, mais especificamente na área de Português Brasileiro como Língua Estrangeira.

Essas reflexões nos conduzem a constatar, a partir de uma dimensão micropolítica, o reflexo da macropolítica neocolonial, que insiste em aprisionar, em receptáculos de substância e atributo, os conceitos geradores das sociedades modernas e pós-coloniais. Isto é, categorias sociais que delimitam e tracejam rotas de sentido e de validade às mais diversas manifestações linguísticas e culturais, a partir de uma lógica rigidamente hierárquica e dicotômica, em que as categorias de língua, raça e nação vão se articular para projetar uma brasilidade, em termos culturais e linguísticos.

Para tanto, os atravessamentos históricos e culturais na formação do português brasileiro rasuram o paradigma hegemônico instalado na ideia de língua nacional. Por este caminho, nos propusemos a refletir acerca da categoria político-cultural da amefricanidade na formação do pretoguês. E a partir desse lugar afrorreferenciado de língua e cultura brasileira, pensamos o entre-lugar de mediação crítico-reflexiva do professor para uma postura antirracista no ensino de PBLE.

Nesse sentido, o acontecimento de um curso de Português Brasileiro no atual contexto social, cultural e político que experienciamos, na segunda década do século XXI, 
faz-nos lançar luz sobre a ideia de língua nacional e percebê-la como uma amarra perpétua do laço colonial e escravocrata, fruto do projeto da modernidade e seus desdobramentos no processo de internacionalização (e ensino) do Português Brasileiro como Língua Estrangeira. Trocando, então, o "apesar de" por o "ainda bem que", a experiência de lecionar português para estrangeiros proporcionou profundas reflexões e inflexões sobre nossas concepções de educação linguística num contexto de ensino remoto emergencial.

\section{O curso de PBLE e suas contribuições para a consolidação das experiências formativas de ensino das/os estudantes de Letras.}

Tendo feito toda essa exposição acerca das bases teórico-epistemológicas do curso de PBLE, enveredamos por uma discussão mais articulada ao campo de experiência do professor-bolsista na condição de estudante do $8^{\circ}$ semestre do curso de Letras da UESC, o que explica o relato em primeira pessoa, a partir de então, nesta seção.

Voltando o olhar para a minha experiência enquanto bolsista do projeto de extensão, posso afirmar que foi muito significativo para a articulação de meus aprendizados no decorrer da Licenciatura em Letras ao novo contexto didáticopedagógico que emergia. Isso fez com que eu reposicionasse concepções e áreas de estudo sobre o objeto central desta graduação: a língua(gem) em uma perspectiva funcional. Neste decurso de reflexões sobre esta área e este objeto de estudo, ampliei meus horizontes de análise, sendo este curso de PBLE a mola propulsora de reflexão e análise sobre o Pretuguês, este continuum da gramaticalização sofrida do português europeu pelo contato com as línguas africanas no projeto colonial de coerção linguística, ou seja, um movimento que vai da incorporação da língua estrangeira ao status de língua materna. Considerando as relações de controle e poder no Brasil, a experiência com as/os estudantes europeus é uma face da rigidez hierárquica do sistema colonial atualizado no século XXI.

Vale ressaltar que estávamos num contexto do ensino remoto emergencial, uma novidade para muitos de nós que vêm de uma formação presencial e para o presencial, o mesmo não foi diferente entre as/os estudantes, que, pelos mais variados motivos, mantinham suas câmeras desligadas e nem sempre participavam oralmente, restringindo-se ao chat do Google Meet. Se, por um lado, éramos demandados sob esse ângulo, de outro, tínhamos uma excelente recepção dos conteúdos e propostas de aula 
por parte dos hispano-falantes, sendo esses a grande maioria concluinte. Vejamos o feedback de alguns de nossas/os estudantes ao longo do curso:

Tabela 4 - Feedbacks

\begin{tabular}{|c|c|}
\hline Nacionalidade & Colombiano \\
\hline Resposta & $\begin{array}{l}\text { Acabei de responder a avaliação do curso e queria dizer que não sei } \\
\text { se essa sempre foi a intenção de vocês, mas achei ótimo que (apesar } \\
\text { dos conflitos que esses tópicos possam ter gerado para algumas } \\
\text { pessoas da classe }(-)-0 \text { ) os recursos textuais procurem questionar } \\
\text { o racismo, o machismo e outros problemas desta parte do mundo. } \\
\text { Estou curioso para saber porque, considerando que os temas dos } \\
\text { exemplos podem ser muitos, vocês optaram por trilhar esse } \\
\text { complexo caminho. Um abraço. }\end{array}$ \\
\hline Nacionalidade & Argentino \\
\hline Resposta & $\begin{array}{l}\text { Tô muito feliz de ver que no Brasil tem gente jovem que dá tanto } \\
\text { valor a língua. [...] Eu quero pedir a explicação sobre a palavra } \\
\text { liberdade... por que livre escreve com " } v \text { "e porque liberdade que é } \\
\text { uma derivação da palavra livre escreve com "b" de bola. Você deu } \\
\text { uma explicação muito boa, e eu posso querer que você me dê essa } \\
\text { explicação porque eu posso passar pros meus alunos, o dia que eu } \\
\text { tiver aula explicar o porquê, porque assim eu entender a língua. } \\
\text { (transcrição de áudio) }\end{array}$ \\
\hline
\end{tabular}

Fonte: Os autores, 2021.

\section{Considerações finais ${ }^{6}$}

Por fim, é preciso destacar que, para nós, professores que atuaram nesse curso, foi uma aprendizagem muito significativa, conduzindo-nos a uma estima e compromisso maior pelo ato de ensinar, e tal pensamento nos remete à ideia da pedagogia da busca, ou seja, na condição de professores e pesquisadores, precisamos buscar aperfeiçoamentos e novas formações para melhor atender às necessidades dos nossos alunos.

Com essa experiência, constatamos, ainda, que a formação docente e o ensino de PBLE devem considerar as especificidades corriqueiras e cotidianas da vida linguística no

\footnotetext{
${ }^{6}$ Para as considerações finais, retomamos a $1^{\mathrm{a}}$ pessoa do plural, diferentemente da seção anterior, em que apresentase o relato de experiência do professor-bolsista, um dos autores deste artigo.
} 
Brasil, levando em conta as contribuições negra e indígena na formação do vernáculo brasileiro. Ademais, é preciso assegurar um efetivo processo de ensino e aprendizagem em que compareça a mediação cultural e linguística. Dessa maneira, os sujeitos envolvidos no processo de desestrangeirização (ALMEIDA FILHO, 1993) poderão apropriar-se da língua num gesto de reelaboração, reinvenção e reinterpretação de si e da inscrição do corpo-palavra no mundo.

\section{Referências}

ALMEIDA FILHO, José Carlos P. Dimensões Comunicativas no Ensino de Línguas. Campinas: Pontes, 1993.

ALMEIDA, Silvio Luiz. Racismo Estrutural. São Paulo: Editora Jandaíra, 2020.

BAKHTIN, Mikhail. Marxismo e filosofia da linguagem. São Paulo: Hucitec, 1997.

BORGES, Elaine Ferreira do Vale. Comunicativo e comunicacional no ensino de línguas. Linguagens e Diálogos, Rio de Janeiro, v. 3, n. 1, p. 29-42, 2012.

FERREIRA, Aparecida de Jesus. Teoria racial crítica e o letramento racial crítico: narrativas e contranarrativas de identidade racial de professores de línguas. Revista da $A B P N$, Guarulhos, v. 6, n. 14, p. 236-263, out. 2014.

GONZALEZ, Lélia. A categoria político-cultural de amefricanidade/Cultura, etnicidade e trabalho. In: RIOS, Flávia; LIMA, Márcia (org.). Por um feminismo afro-latinoamericano: ensaios e intervenções. Rio de Janeiro: Zahar, 2020.

MOITA LOPES, Luiz Paulo da. Da aplicação de linguística à linguística aplicada indisciplinar. In: ROCA, Pilar; PEREIRA, Regina Celi. (org.). Linguística aplicada: um caminho com diferentes acessos. São Paulo: Contexto, 2016.

MUNANGA, Kabengele. Negritude: usos e sentidos. Belo Horizonte: Autêntica Editora, 2020.

NASCIMENTO, Gabriel. Raça e resistência ao racismo em atividades de língua inglesa no sul da Bahia. Cadernos de Pesquisa. São Paulo, v. 49, n. 173, p. 208-225, jul./set. 2019. Disponível em: <https://www.scielo.br/j/cp/a/NJG4N6vWRLrs3zy4cnzYmBR/?format=pdf\&lang=pt. > Acesso em: 16 dez. 2021.

ZOPPI-FONTANA, Mónica Graciela; DINIZ, Leandro Rodrigues Alves. Declinando a língua pelas injunções do mercado: institucionalização do português língua estrangeira (PLE). Estudos Lingüísticos, São Paulo, v. 37, n. 3, p. 89-119, set./dez. 2008. 